of the same certain and assured value, or to be appraised and measured with the same facility, as the other. It is this sense of insecurity that makes so many halt at this point, rehearsing for ever their tables and formularies, dealing in a jargon which they mistake for learning, and decline to exchange for it.

Here then, I repeat, is a definite object to be aimed at in lectures upon medicine: the actual exhibition and demonstration of disease, in all its complexity and variety, by means of living illustrations - exercise under a master in the very same problems which must presently be solved alone, with that sort of help to the solution which comes from the possession and the study of "worked examples." We need fear now no competition of the books, for we know that ours are better. I know for myself with what personal satisfaction, after labouring to describe some morbid sound or other aspect of disease difficult to reach hy words, I have led the puzzled listener to the thing itself. Whatever is best in the verbal description gets thus fixed indelibly, while every such diversion is for the student a fresh contribution to that aggregate of experience which is to determine in the future, other things being equal, his relative merit amongst his fellows.

Such teaching must, indeed, always be incomplete, inasmuch as it depends for its illustrations upon the actual material that we have at hand. We cannot, like the books, discourse with the same fluency of hydrophobia and the plague, as of acute rheumatism or pneumonia. Yet the main purpose is not the heaping up of facts, hut rather practice in arranging and interpreting them, and even this incompleteness of illustration is not without its use, for it gives the student a correct view of disease in its true perspective, exposing the unreality of that dead level of official description where every affection is depicted in its turn as thongh all were equally distinct and well defined.

You will say, perhaps, that by this treatment the course of lectures in medicine becomes a course of clinical lectures. And so truly does it, yet not in such manner as to interfere with the lectures we now call clinical. These latter are occasional and unconnected, they deal with some particular case, and point out unusual features of disease. They are controversial and speculative. Systematic lectures, on the contrary (in the strictest sense clinical if they are to be of any use whatever), follow a definite course, from which they only diverge occasionally, when attracted by the nature of their material; they point out not so much the exceptions of disease as its common rule, and show in the flesh in a series of living pictures all the chief articles of the syllabus.

All this inplies, no donbt, much more than sitting at a lecture. The education I am thinking of is not to be got sitting or by any passive attitude whatever. The only question is as to the precise co-operation of teacher and learuer in what must be a common work. Such difference of opinion as exists upon this point is partly explained and justified by considering that different orders of mind need different trainiug. I cannot doubt that some have worked out this nractical knowledge for themselves painfully and laboriously at the bedside, and have obtained their reward at last in a greater acumen and facility of diagnosis than often comes to those who give the hand and are shown the way. Yet for the great majority it is not too much to assume that our guidance and suggestion must go for something, provided only that the spirit of our teaching tends to educate and exercise the pupil's own judgment, not to bind him down to anybody's gospel. And while I am persuaded that no just conception of medicine can ever he conveyed in a series of dogmas, I have no fear whatever lest the frank exposition of the subject in all its ambignity and incompleteness should disturb the proper relation between master and scholar. On the contrary, there comes to this latter of necessity, by the operation of the nore liberal training, a conviction which both maintains the anthority of the teacher, and in due season will form the ground of the student's own self-confidence-the conviction, I mean, that so long as the methods pursued are ripht and thorongh, time and use crntinullily make the way flainer and lessen the probability of error.

Such, then, is the ideal of that medical training which it is the chief business of these lectures to help forwarl. I am far from supposing that it is altorether realisel. There is, indech, a short rejly to all that I have been trying to saly, which 1 hear from yon so often and with such little variation, that I cunnot but think there is some substance in it. You say that there is no time for this sort of teaching, and no need for it; that the student can pass his examination without it. It is not easy to say whether the irony of such a statement is the more bitter as it concerns our present system of medical education or the vigilance of our examining bodies: the importance we attach to that practical knowledge which is the grand aim and end of all medical study, or the pains we take that only those who possess such know: ledge shall have authority to take charge of the sick.

\section{CASES OF ANEURISM ILLUSTRATING DIFFI CULTY IN DIAGNOSIS, AND THE USE OF ESMARCH'S BANDAGE.'}

By WALTER RIVINGTON, M.S. LOND., F.R.C.S. ExG., SURGEON TO TIIE LONDON HOSPITAL.

THE two following cases of aneurism in the lower limb present features worthy of notice. The first case was one of idiopathic aneurism of the anterior tibial artery-a rare affection, and attended in this instance with conditions which invested it with more than usual interest. Being of large size it raised a suspicion that it might be malignant disease, and having been originally mistaken, before it came under my care, for an abscess, and incised, it became the seat of secondary hamorrhage, which, owing to the misguided refusal of the patient to submit to the necessary treatment, led indirectly to a fatal issue. The only means at my disposal for arresting the hæmorrhage, whilst giving the patient a chance of cure, was Esmarch's bandage, and it will be seen that, after one application for an hour without result, a second application for an hour and a quarter on the following day, when the hæmorrhage occurred, produced the desired coagulation in the tumour. This success, however, was itself unsuccessful, for the force of the arterial circulation was reduced below the point needed to return the blood through the already obstructed veins, and gangrene of the foot ensued. Amputation was persistently declined, and death resulted. The following is the outline of the case :-

CASE 1.-Arthur $\mathrm{W}$ - aged fiftr-eight, of rather a spare habit, was armirted into the London Hospital on the 8th February, 1877. His family history was very good, and he had always been a strong, able-bodied workng man. He had been at sea for many years as a butcher, and for the last nine years had been a common labourer in London. He had always been a regular, temperate man. There was neither history nor appearance of syphilis, and the only severe illuess which he had experienced was one attack of intermittent fever. He had never suffered from rheumatism, or been troubled with his leg. Ahout six weeks before admission (the day before Christmas), whilst walking up stairs he felt a pain in his right leg, just below the knee, and on looking at it, he found a swellung not larger round than a halfuenny, and the same night he felt it pulsating under his fincrers. Four days later he had medical advice, and was told that the swelling was an abscess. He was recommended to poultice it, and this he continued to do for about four weeks. The swelling enlarged rapidly every day, and the whole leg becane larger and more painful. Two days before admission a small aperture was made in the tumiour. The blceding was fiee, and, according to the patient's lescription, "the blood sparted un in a stream like a fountain." A compress ant bandage were inmediately put on, and the bleeding was checked.

The patient was advised to come to the hospital, and he did so two days later. There was then a large oval swelling commencing in few inches below the rirht knee, and with the long axis corresponding to the axis of the limb. It looked red and inflamed, and on palpation gave a feeling of $s \in \mathrm{mi}$ Ilnctuation. Over the centre of the swelling there was a small punctured wound which was elosed and partly healed. On pressing the scab off a few drons of pus exuded. The lousc-siurgeon introduced an exploring needle through the a perture, and blood came trickling aloug the groove. Being 
doubtful about the witure of the ciss, he sent the patient to bed to await my examination.

When $I$ saw the patient in the ward, the aspect of the tumour at once suggested an aneurism. On pressing with the ends of my fingers firmly on the tumour, a strong pulsation was communicated to them, and examination with the stethoscope revealed a lond bruit of a rather rasping character. The swelling had more of a bruised than an inflamed appearance, but the skin was hotter than that of the opposite limb. The swelling extended round the outside of the leg to the posterior aspect; the calf bulged and pulsated. Large glands were found in the groin. Pressure with fingers on the calf communicated an impulse to fingers placed over the tumour in front. Compression of the femoral arrested the bruit and pulsation. Over the tumour, and especially behind, large veins were seen ramifying. The font was a little swollen, and the tibial arteries beat fcebly. The only question in my mind was this, Is the tumour an aneurism or a pulsating cancer?-a question to which I deferred giving a decided answer; but on this point I was clear, that the case should at once be treated as an aneurism by means of com. pression, the effects of compression to be carefully watched, and action taken accorling to circumstances. Hence I directed that the patient should be brovght down from the upper ward, where he was lying, to the accirlent ward, where he could be under the immediate eye of the house-surgeon, and that a tomrniquet should be apulied without delay.

The following day it was found that the effect of the compression which had been kept up through the night had been to dininish the impulse in the swelling. Some comparative measurements of the two limbs were made by Mr. Buxton, the dresser, with the following results :- The circumference $2 \mathrm{in}$. below the head of the fibula in the sound imb was 10 in., and in the diseased limb 12 ; at $3 \mathrm{in}$. distance, 10 and 14 ; at 4 and $5,10 \frac{1}{2}$ and 15 ; at $6,9 \frac{3}{1}$ and $14 \frac{1}{2}$; at 7,9 and $13 \frac{1}{1}$; at 8,8 and $12 \frac{1}{4}$; at $9,7 \frac{3}{4}$ and $11 \frac{1}{2}$; and at $10,7 \mathrm{in}$. and 10.1 respectively.

The patient was seen early on Saturday, the 10th, by two of my senior colleagues. Both inclined to the view that the tumour was of a malignant nature ; one agreed with me that, in the existing uncertainty, it was desirable to continue treating the case as aueurismal by means of compression holding amputation in reserve; and the other gave a decided opinion in favour of early amputation. A third colleague saw the case, and balanced the points on both sides very carefully without committing himself to a pronounced conclusion.

I mention these details to show the difficulty that often exists in cascs of anemism of coming to a correct diaguosis. In favour of malignant tumour were the size of the swelling, the enlarged grlands in the groin, and the dilated veins over the tumour. The chief ohjectious to the view of malignancy were, that the tumour could not be traced into connexion either with the fibula or with the tibia, and the character of the bruit. The bruit was loud and rongh, andible along the tibia, over the knce-joint and interual malleolus. At one point-riz., the upper part of the anterior aspect of the swelling-Dr. Turner noticed that the bruit was double. I determined, therefore, to continue compression till Monday, if nothing should arise meanwhile to demand interference. In case of hamorrhige, which seemed not improbable, owing to the artificial opening on the face of the tumonr, there would have been no difficulty in temporarily arresting it with the touruiquet or Eimarch's elastic tube, and I gave directions that the patient should be constantly attended.

On Sunday I found that the swelling har increased in size, measuring an inch more in the centre than on the previous day, notwithstanding the application of the tourniquet. The pressure of the instrument gave the patient considerable discomfort, but this was relieved by hypodermic injections of morphia. On Sunday afternoon I determined to try the effect of the application of Estnarch's bandage, and I adjusted it in the way recommended by Mr. Wagstaffe, passing it quite lightly over the tumour, and firmly above it, as far as the midile of the thigh, where it was pinned. Cottonwool was placed over the foot and leg before the application of the bandage. The bruit and pulsation were arrested for one hour, and at the end of that time the bandage was removed, after screwing up the tourniquet. After awhile I loosened the tourniquet gradually, and in a few minutes prisation became evident, and both it and the bruit were reestablished as markedly as before. The tourniquet was reapphed, kept on all night, and not removed till the middle of the following day. About one o'clock the clot plugging the aperture into the aneurism gave way aud severe hromorrhage came on, burstiug through the cottus-wool and bandage round the limb. The bleeding was arrested by the tourniquet. I was summoned to the patient. I was abont to arjust Esmarch's bandage with the strap for temporary security against hæmorrhage and to ascertain its effect upon the tumour, and I was about to urge upon the patient the necessity of leaving our hands unfettered in regard to ampu. tation, when the patient informed me that he would not submit to any operation. The hæmorrhage had diminished the tension of the swelling, and so far altered it as to convince me that it was a false aneurism and not a malignant tumour. The only measure which the patient would tolerate was compression, but compression, whether digital or instrumental, with the ordinary tourniquet was ineffectual, and could not be maintained continuously so as to preserve the patient from the danger of recurrence of hæmorrhage. The only resources left were Esmarch's bandage and injection of perchlnride of iron, or a combination of the two. I preferred Esmarch alone, and placed the patient under chloroform during its adjustment. Mr. Hutchinson, whose visiting day it was, saw the patient while the strap was on, and exerted his persuasive powers in vain to induce him to leave the surgeon unfettered. At the end of an hour and twenty minutes the baudage was removed, digital compression being maintained for some time longer. The limb was placed in cotton-wool. Pulsation had not wholly ceased in the aneurism after the removal of the elastic tube, and the circulation promised to become re-established in the leg and foot. But when coagulation in the sac became complete, and all pulsation and murmur were abolished, it was found that whilst the heel became hotter than usual, and showed marked evidence of the opening of a collateral circulation, the anterior part of the foot and the toes were cold. The veins on the dorsum became distended, and the surface mottled. On the following day the toes were cold and had lost sensation. Am. putation was again urged without success. The tumour gave exit to venous blood, and became much diminished in size. Day by day the gangrene advanced. On the fourth day after arrest of the pulsation the disorganisation had extended to the leg. The orifice of the aneurism now began to ulcerate, and to give exit to black blood and broken-down clot. In spite of the pain and the danger to his life, the patient adhered with a Turkish fanaticism to his resolution not to part with his limb. On the 19th a line of demarcation had hecome evident in the lower third of the leg, but the constitutional state of the patient had become serious; quick pulse, hich temperature, basi-pneumonia, flushed and anxious face, anorexia, want of rest and delirium, and in a few days more the scene was closed. Towards the end he misht have been persuaded to submit to amputation, but it was too late for recovery, and I did not press him further.

Locally the post-mortem examination disclosed a nearly complete solution of continuity of the anterior tibial artery, and its ruptured part was occupied by a sac composed of the surrounding tissues and blood-clot. The sac was filled with broken-down coagulum. The aneurism was situated a few inches from the origin of the artery, and this portion contained a clot of partially decolorised fibrin, and the clot extended into the popliteal artery. It was by no means clear that the decolorised portion of the clot, which occupied the popliteal artery, had not formed at the time that the blood coagulated in the sac.

The second case was one of aneurism of the popliteal artery, projecting not in the popliteal space, but on the inner side of the limb, and thus inviting the unsusperting practitioner to mistake it for some other tumour. The notes of the case yield the following history :-

CASE 2. - Heury C- , forty-four, a soldier, a wellnourished man, heicht $5 \mathrm{ft} .9 \mathrm{in}$. was admitted into the London Hospital under my care on August 20th, 1879, sutfering from a tumour occupying the lower part of the inner side of the left thigh. He had served in the Crimean war and the Indian Mutiny. In 1858 he had a sore on the penis, which was followed by sore-throat, but not by rash, loss of hair, or other recognised sequelæ of primary syphilis. He had been accustomed to march fifteen miles a day for several weeks together. He had never had rhenmatism or gout. In 1864 he had fever in India, and in 1872 he suffered from jaundice. He was discharged from the army in 1874 , and since that time he had been a clerk. In the early part of last June he began to suffer from pains of a darting cha. racter in the left ham, agrravated at night when he was warm in bed. Fourteen days later he noticed on the inuer 
side of the loft ham a small lump, which was painful, and gradually got larirer and more painful. At times when he was out walkincr it would become so painful that he would have to stop and raice his leg, and this always relieved the pain. He consulted a hospital surgcon. Scott's dressing was applied. Removal was suggested, and the patient was allowed to walk about as usual. After his admission into the hospital a week later, my attention was called to him by my house-surireon, who told me that there was an interesting tumour which he wished me to examine. I found an oval tumour of the size of a large orange, or of a shaddock, situated in the hollow above the inner condyle of the femur, distinctly circumscribed and solid, On grasping it with my hand, pulsation was felt. The pulsation was not a mere impulse, or pushing in-
wards of the tumour en masse, but of the generally expansile character of an ordinary aneurism, communicated to the hand in every direction. There was a loud, harsh, rasping bruit. On compression of the femoral artery both bruit and pulsation ceased. Pulsation could not be detected in the popliteal artery in the normal situation of the vessel in the ham, but it was felt in both the tibial arteries, and the limb below the aneurism was of natural warmth and aspect. The patient was anæsthetised with chloroform, and Esmarch's bandage and strap were applied for an hour. Before removal of the strap the femoral artery was compressed, and on gradually allowing the admission of blood into the limb by the main channel, a slight pulsation and bruit could still be detected. A third of a grain of morphia was administered hypodermically, and digital compression was kept up for three hours, at the end of which time no pulsation could be felt. The patient complained of a burning pain in the foot, which was warmer than the light foot. The leg and thigh had been enveloped in cotton-wool and a flannel bandage immediately after Esmarch's bandage had been removed, and this casing was kept on till the following day. On the morrow, the $22 \mathrm{nd}$ of August, he still complained of a burning pain in his foot; there was neither pulsation in the tumour nor swelling of the limb. On the 25th it was noted that the pain in the foot had passed off, and that the tumour had diminished in size. On the 12th of September the tumour was less than half the original size, hard, not painful, with good pulsation in the tibial arteries. On October 3rd the patient was discharged cured. I must add a word of praise for the care and attention given to the case by my house-surgeon, Mr. J. G. Clark, and the dressers.

These cases raise several points of importance relating to Esmarch's bandage as a means of treating aneurism of the limbs, and to the diagnosis of aneurismal tumours. The value of Esmarch's bandage in the treatment of aneurism of the lower limb has been clearly established by several successful cases published in the journals or brought before the Societies. It is well known, however, that it is not uniformly successful by itself, and not always when aided by instrumental and digital compression. Sometimes it might prove injurious. It is quite possible that with the greatest care it might induce sloughing of the tissues over the sac, and it might also have the effect of causing gangrene of the limb through an excess of coagulation. It is scarcely possible to state beforehand whether a case is likely to be benefited by the treatment. One or two cases have come under my observation in which, after prolonged application of Esmarch's bandage, the symptoms were barely relieved, but after the lapse of a certain time from the application the aneurism ceased, as it were, spontaneously to pulsate. My impression is that the most favourable cases for the use of Esmarch's bandage are aneurisms of moderate size, firm and not too near the skin. My first case was decidedly an unfavourable case for Esmarch's bandage, and the bandage was only applied at the first trial for the purpose, if possible, of avoiding amputation, or the less hopeful procedure of laying open a large sac and tying both ends of the anterior tibial artery; and at the second trial, with a view to arrest hemorrhage, place the patient out of immediate danger, and give him a chance of saving a limb which he seemed to prize more dearly than his life. Ligature of the femoral was of course out of the question under any circumstances, as it must have induced gangrene. Amputation had most in its favour, and amputation I should have performed the moment that $I$ found that coagulation of the blood in the sac was incompatible with the life of the limb below. The extension of the clot in the sac into the anterior tibial above the sac, and even the lower part of the popliteal, is certainly sug. gestive of the possibility of gangrene arising in other cases from a like cause; and I know not how the occurrence can with certainty be prevented. Prima facie it would seem that the pressure of Esmarch's bandage might squeeze the blood from the sac into the feeding artery and even above it, and that this blood, remaining when the strap is applied, might coagulate, plug the vessels, and not be washed into the sac again when the current of blond through the main channels is restored. But I cannot speak with any certainty as to the extent of the liability to gangrene from such an accidental occurrence.

Of the two methods of applying Esmarch's bandage to an aneurism-viz., fixing the strap aud removing the bandage, and pinning on the bandage without the strap, I think the former is preferable, as we can then make observations on the tumour such as might determine a doubtful diagnosis. But even here a caution is necessary. Free manipulation of an aneurism after the application of Esmarch's bandage might give rise to the very occurrence which we wish to avoid-viz., pressing blood or congulum into the neighbouring vessels; and $I$ am not altogether free from a remote suspicion that something of the kind happened in my first case at the second application of Esmarch's bandage, when a most excellent and careful surgeon made a minute manual examination of the tumour. It may or may not have been so. The liability to such an issue did not strike me at the moment, but it has arisen in my nind in the course of a retrospect of the case. At all erents it may be wise to bear the possibility in mind.

The only other remarks which $I$ have to make concerning Csmarch's bandage are : (1) that even when it is passed as lightly as possible over the sac some of the blood appears to be squeezed out of the sac, at least in my own cases in which this was done the sac seemed considerably smaller than before; and (2) that it might be advantageous, where the bandage aided by digital compression had failed, to inject a little perchloride of iron into the sac in combination with another application of the bandage. This treatment, how ever, I would only suggest for exceptional cases. In my first case, in which there was a ready-made aperture, I should have resorted to injection of the perchlorice in combination with Esmarch's bandage, if the bandage alone had not sufficed to coagulate the blood.

(To be concluded.)

\section{ON THE PHYSICAL DEVELOPMENT OF CHILDREN ; \\ OR, THE DEARING OF ANTHROPOMETRY TO HYGIENE.}

BY PERCY BOULTON, M.D., M.R.C.P. LOND., PHYSICIAN TO THE SaMaRITAN hOSPITAL For WOMEN AND CHILDREN.

BoTH in England and abroad much attention has of late been devoted to the study of anthropometry, and in its medical aspect $I$ have for many y ears worked at the subject. I believe that it is likely to become a most valuable aid in preventive medicine, and merits the attention of everyone interested in the healthy growth and development of children.

A profession as far-reaching as the medical embraces everything that has to do with man materially in health and disease. It is chiefly owing to improved medical and surgical skill, together with sanitary science, that in recent years the value of life has been so considerably enhanced, and by prevention of disease we are further able to do much towards raising man to the full perfection of his physical being, so that the whole race should become by degrees man for man nearer the ascertained healthy type. From the physical point of view it is during the period of growth that mischief is done or can be averted, and hence the value of a reliable standard of height for weight during that period of childhood which lies between three and five feet. During this stage the arrested growth, if discovered, can generally be remedied, and if weighing and measuring were more systematically practised it would rarely escape notice.

When I commenced weighing and measuring ten years ago correct averages were nnkuown to me, and $I$ had no idea how much a child should grow in a year, so that the scales and measure were practically useless. This child 